\title{
Letter to the editor regarding "Atlantoaxial dislocation due to os odontoideum in patients with Down's syndrome: literature review and case reports"
}

\author{
Fraser C. Henderson $\mathrm{Sr}^{1,2}$ (D) Clair A. Francomano ${ }^{3} \cdot$ Peter C. Rowe $^{4}$ \\ Received: 30 August 2020 / Accepted: 8 September 2020 / Published online: 17 September 2020 \\ (C) The Author(s) 2020
}

\section{Dear Editor:}

We have read with interest the excellent review of Down syndrome by Sergeenko et al. [1], in which they bring to attention the frequent occurrence of atlantoaxial instability (AAI) in Down syndrome (DS), the importance of directed radiological assessment, and the association of AAI with os odontoideum, ligamentous laxity, low bone mineral density, low muscle tone, and excessive joint flexibility.

We would like to draw a parallel with another set of genetic disorders, which are characterized by ligamentous laxity, excessive joint laxity, and frequently, low bone density and also have a higher than expected risk of AAI: the hereditary connective tissue disorders (HCTD), including Ehlers-Danlos, Loeys-Dietz, Marfan, and Morquio syndromes [2].

Fraser C. Henderson, Sr

henderson@fraserhendersonmd.com

1 Department Neurosurgery, University of Maryland Capital Region Health Center, Cheverly, MD, USA

2 Metropolitan Neurosurgery Group LLC, 1010 Wayne Avenue, Suite 420, Silver Spring, MD 20910, USA

3 Department of Medical and Molecular Genetics, Indiana University School of Medicine, 975 W. Walnut Street, IB 130, Indianapolis, IN 46202, USA

4 Department of Pediatrics, Johns Hopkins University School of Medicine, 200 N. Wolfe Street, \#2077, Baltimore, MD 21287, USA
In both DS and the HCTD, the clinical diagnosis of AAI can be challenging because of the many comorbid conditions and the musculoskeletal symptoms caused by the generalized joint hypermobility. In both DS and the HCTD, AAI usually manifests in childhood and adolescence (when there is greatest ligamentous laxity) or following minor trauma, and neurological deterioration then occurs over several years. In DS, AAI may cause quadriparesis or quadriplegia with neck flexion, whereas in HCTD, AAI causes severe headache, visual symptoms, syncope or pre-syncope, dysesthesias, nausea and tinnitus, hyperreflexia, and sensory changes due to rotational instability between $\mathrm{C} 1$ and $\mathrm{C} 2[3,4]$.

In DS, screening for AAI has not been reliable, and imaging studies do not correlate well with the risk of myelopathy. Similarly, standard imaging studies fail to show the rotational instability in the HCTD. In these conditions, diagnosis of AAI requires dynamic imaging. In DS, AAI results from incompetence of the transverse odontoid ligament, demonstrated by flexion and extension imaging of the cervical spine (Fig. 1). In HCTD, AAI is caused by incompetence of the alar ligaments, demonstrated on rotational CT by excessive angular displacement between the atlas and the axis (Fig. 2) or by excessive translation on lateral tilt of the neck $[4,5]$.

Symptoms of the cervical medullary syndrome and tenderness over the C1-C2 joint should prompt suspicion of AAI. Directed neurological exam and imaging are necessary to diagnose clinically significant AAI in these populations $[2,4]$. We concur with Sergeenko et al. that posterior stabilization and fusion are reserved only for patients who fail a thorough course of non-operative management. 


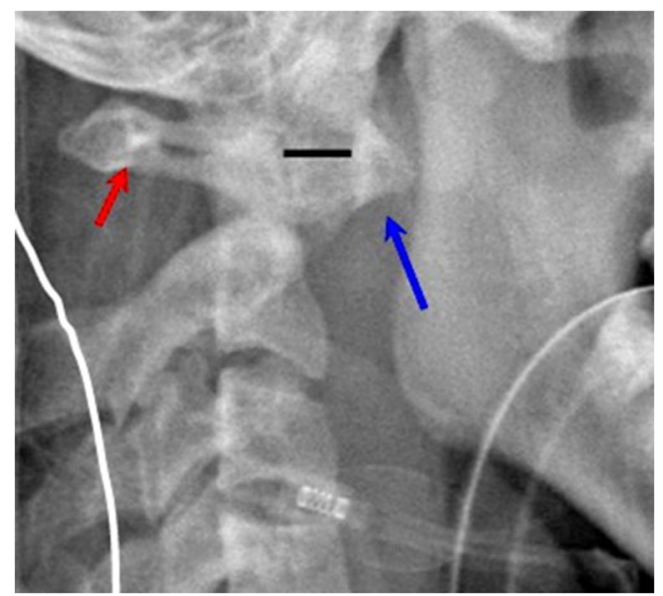

Fig. 1 Lateral cervical spine $\mathrm{x}$-ray demonstrates atlantoaxial instability (AAI) in Down syndrome. In this case, mild flexion of the neck demonstrates a widened atlanto-dental interval (solid bar) between the anterior tubercle of $\mathrm{C} 1$ (long arrow) and the odontoid process that exceeds the pathological threshold in the adult of $3 \mathrm{~mm}$. The spinal canal (small arrow) is substantially diminished and results in spinal cord compression

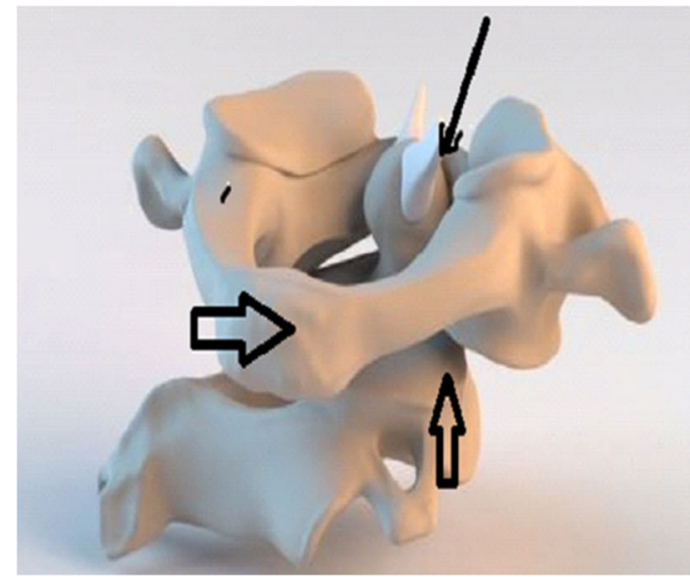

Fig. 2 The model in the left image demonstrates the rotary subluxation (AAI Fielding type 1) that occurs with the hereditary connective tissue disorders. With the rotation of the $\mathrm{C} 1$ ring (large black arrow), the atlantodental interval (small solid arrow) remains normal $(<3 \mathrm{~mm}$ ), but the facet joint (vertical arrow) is subluxed with more than $80 \%$ loss of facet

\section{Compliance with ethical standards}

Conflict of interest On behalf of all authors, the corresponding author confirms there are no conflicts of interest.

Open Access This article is licensed under a Creative Commons Attribution 4.0 International License, which permits use, sharing, adaptation, distribution and reproduction in any medium or format, as long as you give appropriate credit to the original author(s) and the source, provide a link to the Creative Commons licence, and indicate if changes were made. The images or other third party material in this article are included in the article's Creative Commons licence, unless indicated otherwise in a credit line to the material. If material is not included in the article's Creative Commons licence and your intended use is not permitted by statutory regulation or exceeds the permitted use, you will need to obtain

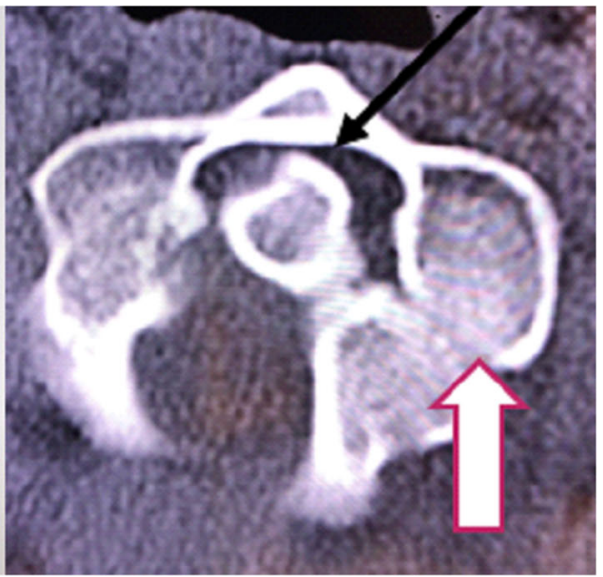

overlap, and the angular displacement between $\mathrm{C} 1$ and $\mathrm{C} 2$ exceeds the pathological threshold of 41 degrees. On the right, the cervical spine CT (axial view through the interface of $\mathrm{C} 1$ and $\mathrm{C} 2$ ) shows the loss of facet overlap (vertical white arrow), but normal atlanto-dental interval (black arrow), representing a rotary subluxation, Fielding Type 1

permission directly from the copyright holder. To view a copy of this licence, visit http://creativecommons.org/licenses/by/4.0/.

\section{References}

1. Sergeenko O, Dyachkov K, Ryabykh S et al (2020) Atlantoaxial dislocation due to os odontoideum in patients with Down's syndrome: literature review and case reports. Childs Nerv Syst 36:19-26

2. Henderson FC Sr, Austin C, Benzel E et al (2017) Neurological and spinal manifestations of the Ehlers-Danlos syndromes. Am J Med Genet C: Semin Med Genet 175(1):195-211 
3. Choi K, Kim J, Kim J et al (2013) Rotational vertebral artery occlusion mechanisms and long-term outcome. Stroke 44:1817-1824

4. Henderson FS, Rosenbaum R, Narayana M et al (2020) Atlanto-axial rotary instability (Fielding type 1): characteristic clinical and radiological findings, and treatment outcomes following alignment, fusion, and stabilization. Neurosurg Rev
5. Joaquim A, Ghizoni E, Tedeschi $\mathrm{H}$ et al (2015) Radiological evaluation of cervical spine involvement in rheumatoid arthritis. Neurosurg Focus 38(4):E4

Publisher's note Springer Nature remains neutral with regard to jurisdictional claims in published maps and institutional affiliations. 